\title{
User Quality of Experience of Mulsemedia Applications
}

\author{
ZHENHUI YUAN, Dublin City University \\ SHENGYANG CHEN, Dublin City University \\ GHEORGHITA GHINEA, Brunel University \\ GABRIEL-MIRO MUNTEAN, Dublin City University
}

\begin{abstract}
User quality of experience (QoE) is of fundamental importance in multimedia applications and has been extensively studied for decades. However, user QoE in the context of the emerging multiple-sensorial media (mulsemedia) services, which involve different media components than the traditional multimedia applications, were not comprehensively studied. This paper presents the results of subjective tests which have investigated user perception of mulsemedia content. In particular, the impact of intensity of certain mulsemedia components including haptic and air-flow on user-perceived experience are studied. Results demonstrate that by making use of mulsemedia the overall user enjoyment levels increased by up to $77 \%$.

Categories and Subject Descriptors: H.1.2 [User/Machine Systems]: Human factors; H.5.1 [Multimedia Information Systems]: Artificial, augmented, and virtual realities; H.5.2 [Information Interfaces and Presentation]: User Interfaces—Evaluation/methodology

General Terms: Design, Experimentation, Human Factors

Additional Key Words and Phrases: Mulsemedia, olfaction, haptic, air-flow, cross-modality, perception, feeling
\end{abstract}

\section{INTRODUCTION}

The latest advances in human computer interaction (HCI) technologies enable creation and usage of applications that engage multiple human senses. A new paradigm has been introduced to extend the traditional multimedia applications with additional media components and is referred to as multiple sensorial media (mulsemedia) [Yuan et al. 2013] [Ghinea and Ademoye 2010b; Ghinea et al. 2011]. In general, mulsemedia applications include any combination of traditional media components such as text, graphical images, video and audio, as well as non-traditional media such as olfactory, haptic, skin-sensorial (e.g. air-flow, temperature, humidity, etc.), gustatory, etc. However, to date most solutions have only engaged two human senses: visual and audio. Currently, widely-spread multimedia applications are limited in their ability to provide an immersed sense of reality to their users, which would have the potential to increase their perceived quality levels. For instance, when delivering multimedia content, users cannot feel real environmental elements such as the scent of flowers, air motion of the ocean wind, haptic effect of a push, etc. Additionally there is a lack of in-depth investigations of how these elements would affect user perception of the content delivered to them.

This paper fills this gap and performs a detailed study on how mulsemedia content affects user quality of experience (user QoE) as perceived by the users subjected to multi-sensorial stimuli. An important contribution of this research is the identification, classification and quantization of user preferences for various individual sensorial components of mulsemedia streams. In particular this study enabled us to statistically learn and analyze users' preferences in terms of ranking of sensorial media types, intensity level, mulsemedia categorization, etc. in relation to mulsemedia applications. Another important contribution is measuring the user QoE of mulsemedia in terms of haptic and air-flow effects via extensive subjective tests, complementing the olfaction-only mulsemedia QoE tests reported in [Ghinea and Ademoye, 2010a, 2012; Murray et al., 2013; 2014]. These tests employed a novel mulsemedia presentation system which was developed to deliver audiovisual media data synchronized with haptic and air motion content.

This paper is organized as follows. Section 2 introduces some state-of-the-art related works in mulsemedia communications. Section 3 presents the user preference study of mulsemedia applications based on the on-line questionnaire. Section 4 introduces the subjective test-bed, scenarios and assessment methods of user perception of mulsemedia applications, section 5 analyses the results obtained in the subjective tests and section 6 concludes the paper.

\section{RELATED WORK}

Whilst mulsemedia - as a term - might be new, this does not mean that research fitting the remit of mulsemedia has not been hitherto undertaken or that applications involving mulsemedia experiences haven't 
been created as of yet. Of the latter, one of the first is Sensorama, created by Morton Heilig, the 'Father of Virtual Reality' [Heilig et al., 1962]. This was an arcade-style device, which took users on an immersive 3-D virtual reality bike ride experience through the streets of Brooklyn. Using motion and vibrations, sounds, fans and smells, Sensorama created a multi-sensory experience for users which simulated those sensations one is likely to experience on a motorbike ride. through the streets of Brooklyn. These sensations included the bumpy feeling a rider may experience as he/she travels over cobblestones, as well as the sights, sounds and smells (the aroma of freshly baked bread from the bakery, scents of hibiscus and jasmine from the flower gardens passed) that may be experienced as the rider continues on his journey.

Impressively, Sensorama, was created in the pre-digital age. With the advent of digital technology and with the increasing processing and rendering facilities that it affords, comes an increasing number of varied works which can now be termed mulsemedia. Just when considering olfaction-enhanced mulsemedia as a case study, one of the most notable virtual reality systems involving the use of olfaction reported since Heilig's invention is the fire-fighter virtual reality training system designed by Cater and his team in 1992 [Cater et al. 1992]. Here, the user wears a backpack mounted device, which emits a range of scents, including burning wood, grease and rubber, sulphur, oil and diesel exhaust, through an oxygen mask connected to the device, whilst immersed in the virtual reality environment. Subsequently, Dinh et al. reported on an experimental study carried out which investigated the use of tactile, olfactory, and auditory sensory modalities with different levels of visual information on a user's sense of presence and on the user's memory of details of the virtual experience. In 2006, there was mention that audiences going to see the screening of the movie, The New World, in Japan will be treated to a scented movie experience [NTT Communication, 2006]. However, whilst there were several reports advertising the 'smellovision' experience to-be, it is not quite clear if this actually happened and if it did what the audience's reaction to it was.

Also, at around the same time, researchers of the study reported in [Kahol et al. 2006] presented strategies and algorithms to model context in haptic applications that allow users to haptically explore objects in virtual reality/augmented reality environments. The results from their study show significant improvement in accuracy and efficiency of haptic perception in augmented reality environments when compared to conventional approaches that do not model context in haptic rendering. Indeed, the use of haptics in mulsemedia virtual reality environments has very recently also been the subject of the research reported in [Apostolopoulos et al. 2012]. In [Ishibashi et al. 2004], the researchers reported on a perceptual study carried out to establish an algorithm to provide high quality inter-media stream synchronization between haptic and audio (voice) media objects in a virtual environment. Indeed, synchronization seems to be a common theme across mulsemedia research. Thus, recent work has explored synchronization of olfactory media with audiovisual content [Ghinea and Ademoye, 2010a], whilst [Steinbach et al. 2012] investigated synchronisation issues between different modalities, as well as the integration of video and haptics in resource constrained communication networks. In [Jakesch et al. 2011], a testing procedure was proposed to measure investigated the stability and ecological validity of evaluations with the focus on a multisensory approach involving vision plus touch, touch-only and vision-only conditions. However, with new technologies for rendering alternative (i.e. non video/audio) media continuously -and increasingly - coming to market, one important unanswered question which they raise is that of the associated user experience. This is precisely the focus of the work described in this paper.

\section{STUDY OF USER PREFERENCE OF MULSEMEDIA}

An online questionnaire was designed (see appendix A) to study the user preference of the mulsemedia content. This section presents the questionnaire and analyses the results.

\subsection{Questionnaire Design and Participants}

54 participants took part in this study. Around $70 \%$ of the participants were in the $25-34$ age group, $25 \%$ of participants were in between 18 and 24 years of age, whilst the remaining $5 \%$ were between 35 and 50 years of age.

The questionnaire included questions regarding the participants' preference levels regarding six mulsemedia sensorial components including haptic, olfaction, air-flow, taste, temperature and humidity. Participants were asked to rate their preference levels in response to statements as follows.

(1) "I don't like experiencing haptic sensations when watching multimedia presentations."

(2) "I like experiencing olfactory sensations when watching multimedia presentations." 
(3) "I don't like experiencing tasting (gustatory) sensations when watching multimedia presentations."

(4) "I like experiencing air-flow sensations when watching multimedia presentations."

(5) "I don't like experiencing temperature effects when watching multimedia presentations."

(6) "I like experiencing humidity effects when watching multimedia presentation."

The above statements, in this order, with an equal mix of positively and negatively framed statements, required answers on a six point scale with the following choices: Strongly Disagree, Disagree, Somewhat Disagree, Somewhat Agree, Agree, Strongly Agree.

Additionally, one episode of an imaginary movie script was included in the questionnaire to further investigate users' preferences of the effect of various sensorial media components. For instance, the scenario concerns the type of olfaction, haptic and air-flow effects users expect and their intensity levels (i.e. strong, medium, and weak). Participants were also asked to rank the six types of scent presented to them (i.e. flower, ocean scent, burnt, fuel, rotting body, and rubbish), as shown in the appendix. For each olfaction type, a participant rated it on a 5-point Likert scale anchored with Bad to Excellent, as detailed in the appendix. Additionally, participants were asked to select their preferable haptic and air-flow intensity levels in the movie.

\subsection{User Preference of Sensorial Effects}

Figure 1 and Table 1 present the statistical results of the online questionnaire. User preference levels of the six sensorial effects are classified and computed according to the two types of responses: negative and positive statements, respectively. For questions (1), (3) and (5), both negative responses Disagree and Strongly Disagree with the statements indicate that the corresponding sensorial effect is highly preferred by the subjects. For questions (2), (4) and (6), both positive responses Agree and Strongly Agree indicate that the associated sensorial effect is highly preferred by the participants.

Among the negatively framed statements, when considering the haptic effect, $40.7 \%$ and $24.1 \%$ of the total number of questionnaire participants (64.8\% in total) selected Disagree and Strongly Disagree, when asked if they dislike haptic effects to be delivered alongside multimedia content. Among the positively framed statements, when considering olfaction , $46.3 \%$ and $14.8 \%$ of the number of users $(\mathbf{6 1 . 1 \%}$ in total) selected Agree and Strongly Agree with the statement they like experiencing olfaction sensations, respectively. Similarly, the total percentage of users who selected Disagree and Strongly Disagree for the negatively framed statements in respect of gustatory sense and temperature body sensors are $\mathbf{1 6 . 7 \%}$ and $\mathbf{2 7 . 8 \%}$, respectively. The percentage of users who selected Agree and Strongly Agree for the positively formulated statements on air-flow and humidity are $\mathbf{6 8 . 5 \%}$ and $\mathbf{2 4 . 1 \%}$, respectively. Considering these findings, we organize the user preference levels of the six sensorial effects in descending order as follows:

(1) Air-flow

(2) Haptic

(3) Olfaction

(4) Temperature

(5) Humidity

(6) Gustatory

Following the results of these questionnaire questions, it can be concluded that air-flow, haptic, and olfaction are in this order top three preferred sensorial effects that users would like to experience in the context of mulsemedia content. In the context of the imaginary movie scenario considered, the scores received by the six olfaction types listed to the participants are shown in both Figure 2 and Table 2.

The term Count represents the number of votes received for a certain olfaction type and Average score represents the average scores of certain scent type voted by all the participants. Total score is the total number of votes given by all the participants. By analyzing the results in Table 2, it can be concluded that flower and ocean scent are more preferable in comparison to other olfaction types including burnt, fuel, rubbish, and rotten body. In particular, burnt and fuel are more preferable to rubbish and rotten body and the highest scores for flower and ocean scent were Excellent with 109.92 and 120.9, respectively, indicating that most participants think that encountering flower and ocean scents would represent an excellent experience. Olfaction scents burnt and fuel were voted as Fair with a total score of 116.91 and 143.88, respectively, indicating that most participants have a fair experience level for these scents. Olfaction scents rotten body and rubbish attracted the largest number of votes and the highest scores in the Bad category (i.e. 91.98 and 125.86, respectively), indicating that most participants had a bad experience when presented with these smells. 
Table 1 User Preference Survey of the Six Sensorial Effects

\begin{tabular}{|c|c|c|c|c|c|c|}
\hline \multirow{2}{*}{ Category } & \multicolumn{3}{|c|}{$\begin{array}{l}\text { Sensorial Effects Rated by Negative } \\
\text { Statement (\%) }\end{array}$} & \multicolumn{3}{|c|}{$\begin{array}{l}\text { Sensorial Effects Rated by Positive } \\
\text { Statement (\%) }\end{array}$} \\
\hline & Haptic & Gustatory & Temperature & Olfaction & Air-flow & Humidity \\
\hline STRONGLY DISAGREE & 40.7 & 0.0 & 5.6 & 1.9 & 3.7 & 7.4 \\
\hline DISAGREE & 24.1 & 16.7 & 22.2 & 7.4 & 11.1 & 27.8 \\
\hline SOMEWHAT DISAGREE & 13.0 & 18.5 & 20.4 & 5.6 & 3.7 & 20.4 \\
\hline SOMEWHAT AGREE & 11.1 & 38.9 & 18.5 & 24.1 & 13.0 & 20.4 \\
\hline AGREE & 11.1 & 22.2 & 27.8 & 46.3 & 27.8 & 22.2 \\
\hline STRONGLY AGREE & 0.0 & 3.7 & 5.6 & 14.8 & 40.7 & 1.9 \\
\hline
\end{tabular}

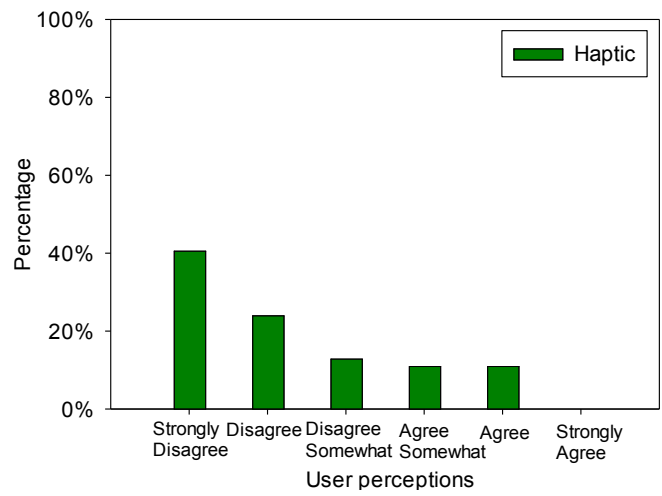

(a) "I don't like experiencing haptic sensations when watching multimedia presentations"

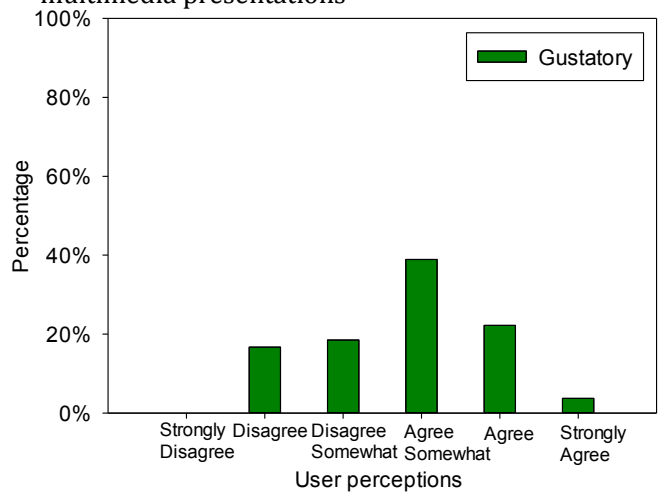

(c) "I don't like experiencing gustatory sensations when watching multimedia presentations"

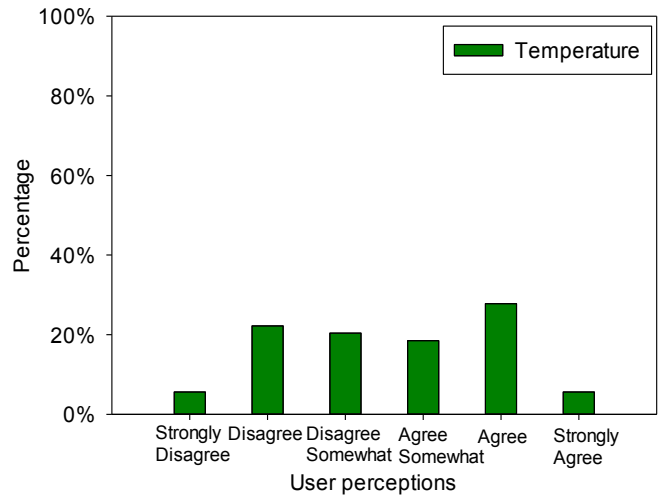

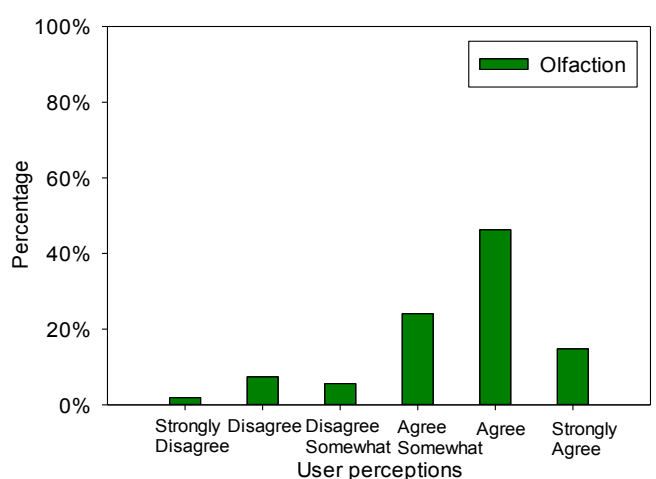

(b) "I like experiencing olfaction sensations when watching multimedia presentations"

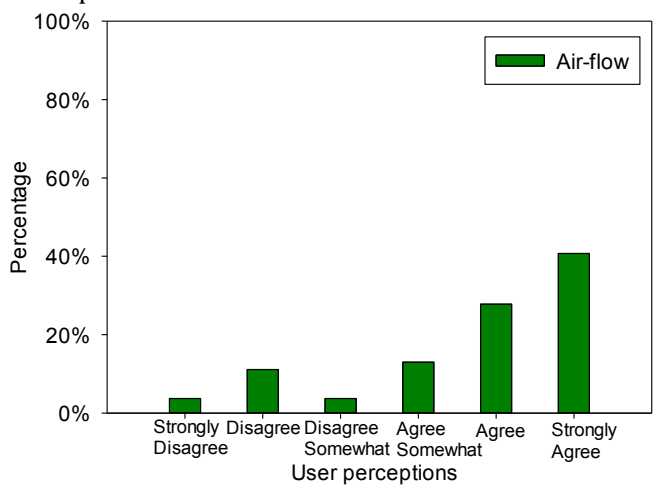

(d) "I like experiencing air-flow sensations when watching multimedia presentations"

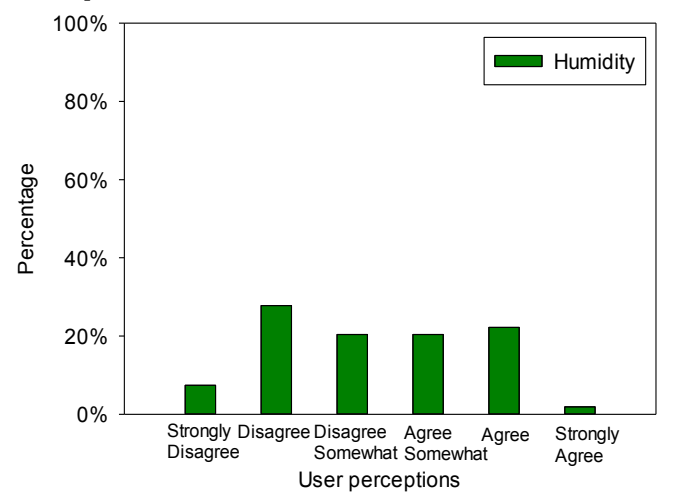

(e) "I don't like experiencing temperature sensations when watching (f) "I like experiencing humidity sensations when watching multimedia presentations"

multimedia presentations"

Fig. 1. User perceptions for the six types of human sensorial effects: haptic, air-flow, olfaction, gustatory, temperature, and humidity. 


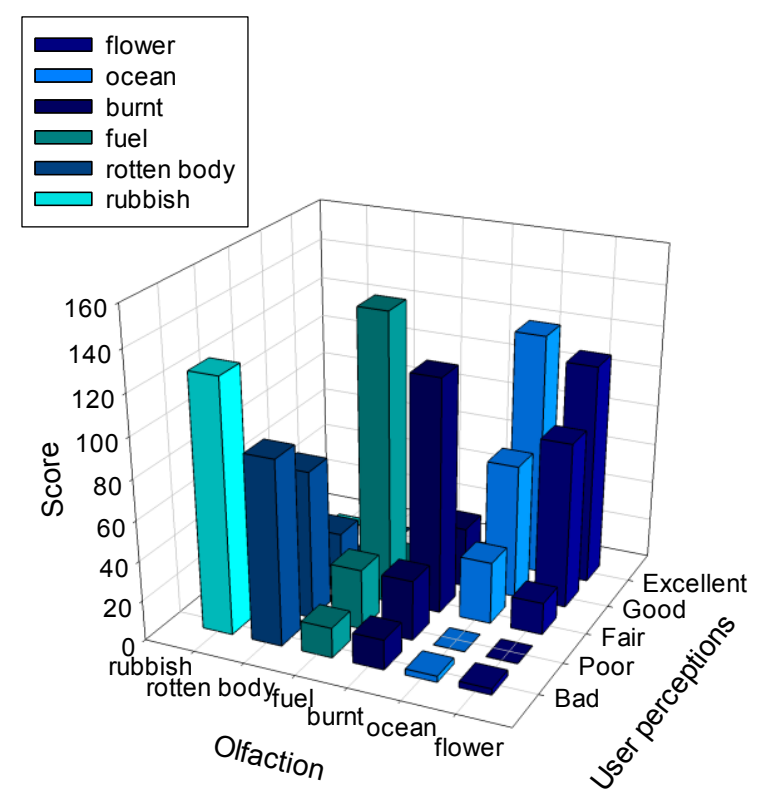

Fig. 2. User Perceptions for Different Types of Olfaction

Table 2 User Perceptions for Different Types of Olfaction

\begin{tabular}{|c|c|c|c|c|c|c|c|}
\hline & & Flower & Ocean & Burnt & Fuel & $\begin{array}{c}\text { Rotten } \\
\text { body }\end{array}$ & Rubbish \\
\hline \multirow{3}{*}{ EXCELLENT } & Count & 24 & 26 & 0 & 1 & 0 & 0 \\
\hline & $\begin{array}{c}\text { Average } \\
\text { score }\end{array}$ & 4.58 & 4.65 & 0.00 & 5.00 & 0.00 & 0.00 \\
\hline & Total score & 109.92 & 120.9 & 0 & 5 & 0 & 0 \\
\hline \multirow{3}{*}{ GOOD } & Count & 18 & 14 & 7 & 2 & 0 & 0 \\
\hline & $\begin{array}{c}\text { Average } \\
\text { score }\end{array}$ & 4.61 & 4.79 & 4.29 & 3.50 & 0.00 & 0.00 \\
\hline & Total score & 82.98 & 67.06 & 30.03 & 7 & 0 & 0 \\
\hline \multirow{3}{*}{ FAIR } & Count & 4 & 7 & 27 & 33 & 8 & 5 \\
\hline & $\begin{array}{c}\text { Average } \\
\text { score }\end{array}$ & 4.00 & 4.43 & 4.33 & 4.36 & 3.75 & 3.50 \\
\hline & Total score & 16 & 31.01 & 116.91 & 143.88 & 30 & 17.5 \\
\hline \multirow{3}{*}{ POOR } & Count & 0 & 0 & 8 & 6 & 17 & 11 \\
\hline & $\begin{array}{c}\text { Average } \\
\text { score } \\
\end{array}$ & 0.00 & 0.00 & 3.75 & 5.00 & 4.35 & 4.27 \\
\hline & Total score & 0 & 0 & 30 & 30 & 73.95 & 46.97 \\
\hline \multirow{3}{*}{ BAD } & Count & 1 & 1 & 4 & 4 & 21 & 29 \\
\hline & $\begin{array}{c}\text { Average } \\
\text { score }\end{array}$ & 3.00 & 3.00 & 3.75 & 3.75 & 4.38 & 4.34 \\
\hline & Total score & 3 & 3 & 15 & 15 & 91.98 & 125.86 \\
\hline
\end{tabular}

Table 3 User Preference Results for Haptic and Air-flow

\begin{tabular}{|c|c|c|}
\hline Intensity & Percentage for Haptic & Percentage for Air-flow \\
\hline Strong & $38.3 \%$ & $41.5 \%$ \\
\hline Medium & $32.7 \%$ & $35.4 \%$ \\
\hline Weak & $18.5 \%$ & $18.9 \%$ \\
\hline None & $9.9 \%$ & $3 \%$ \\
\hline Other & $0.6 \%$ & $1.2 \%$ \\
\hline
\end{tabular}




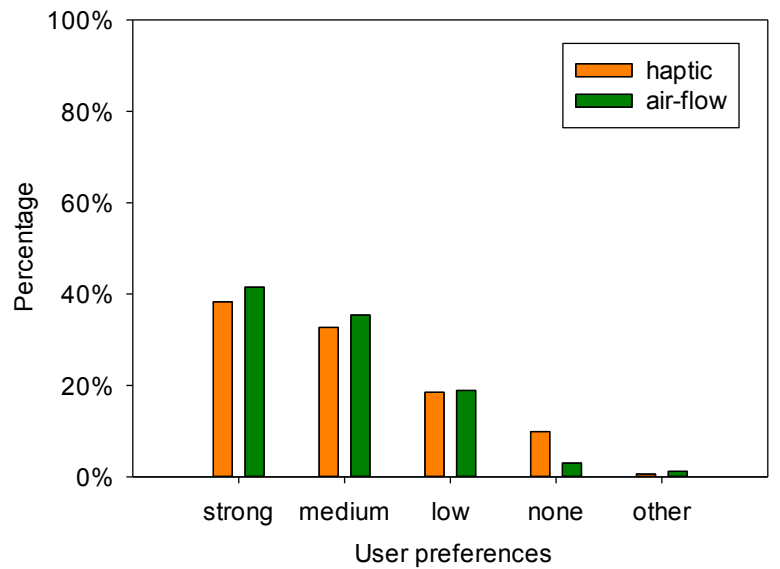

Fig. 3. User Preferences of haptic and air-flow effects

Table 4 Categories of Mulsemedia based on User Preference Survey

\begin{tabular}{|c|c|c|}
\hline Sensorial effect & Category & Example \\
\hline \multirow{3}{*}{ OLFACTION } & Positive & flower, ocean \\
\cline { 2 - 3 } & Neutral & burnt, fuel \\
\cline { 2 - 3 } & Negative & rotting body, rubbish \\
\hline \multirow{3}{*}{ HAPTIC } & Strong & car crash, explosion \\
\cline { 2 - 3 } & Medium & human push \\
\cline { 2 - 3 } & Weak & touch \\
\hline \multirow{3}{*}{ AIR-FLOW } & Strong & hurricane, tornado \\
\cline { 2 - 3 } & Medium & windy weather \\
\cline { 2 - 3 } & Weak & subway passing \\
\cline { 2 - 3 }
\end{tabular}

Figure 3 and Table 3 show the user preference on the intensity levels for both haptic and air-flow sensory mulsemedia components. Among the three intensity levels, the strong intensity level is voted by most participants for both haptic and air-flow effects, with percentages of $38.3 \%$ and $41.5 \%$, respectively. Conversely, the weak intensity level obtains the least participants votes for both haptic and air-flow, with percentages of $18.5 \%$ and $18.9 \%$, respectively.

\subsection{Categorization of Sensorial Effects: haptic, olfaction, air-flow}

By analyzing the olfaction perception results presented in Table 2 and Figure 2, it is shown that the flower and ocean scents receive the highest total scores associated with an Excellent user experience level, burnt and fuel receive the highest total scores associated with a Fair user experience level and rubbish and rotten body obtain the highest total scores associated with a Bad user experience level. In this context, this paper proposes that the olfaction sensorial effect is categorized into three classes: positive, neutral, and negative, respectively, associated with Excellent, Fair, and Bad user experience levels.

A complete analysis of user perceptions of different mulsemedia types (i.e. olfaction, haptic, air-flow) requires extensive investigations. The results of the tests described in this paper suggest that in terms of olfaction media for instance, most participants prefer the flower smell, belonging to the positive class, to the rotting body smell, classified as negative (see Fig. 2). However, although a negative smell (i.e. rotting body) is not as preferred as a positive one (i.e. flower), olfaction media distribution alongside audio-visual components still improves the user overall experience, as it enhances their sense of reality. This has also been shown in [Ghinea and Ademoye, 2012].

Additionally, by looking at Figure 3 and Table 3, 89.5\% and 95.8\% of candidates, respectively, would like to experience different intensities levels (i.e. strong, medium and weak) for haptic and air-flow media components, respectively. This paper thus uses these three intensity levels in the classification of the multi-sensorial media components considered. Therefore, the three most preferred sensorial media types - olfaction, haptic, and air- 


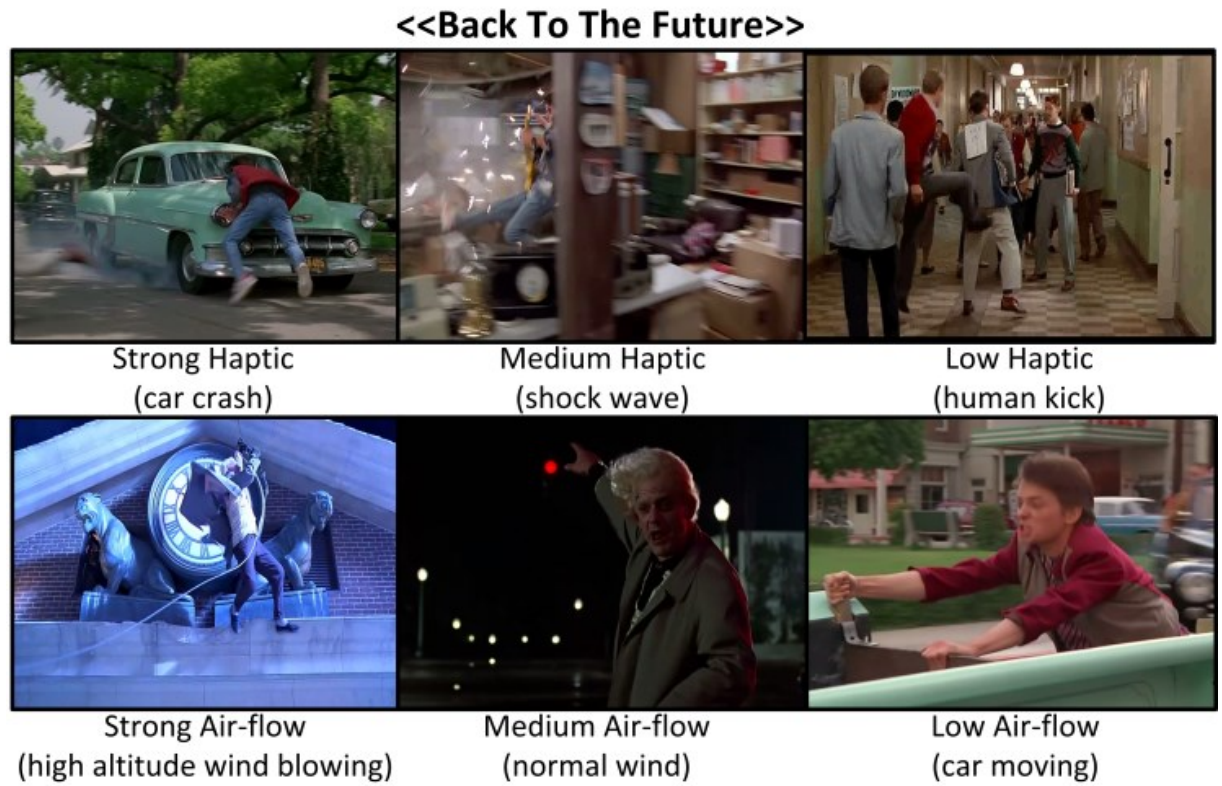

Fig. 4. Sampled frames of mulsemedia test sequences from $<<$ Back To The Future $>$ (Courtesy Of "Back to the Future" as Universal Studios Licensing LLC)

flow - are further categorized as shown in Table 4. These category features can be applied in the context of various mulsemedia content components.

\section{STUDY OF USER PERCEPTION OF MULSEMEDIA}

Olfaction-enhanced multimedia applications have been extensively investigated in [Ghinea and Ademoye 2010a; 2012]. The study presents the results of an experimental study carried out to explore and study the temporal boundaries within which olfactory-data output in an olfaction-enhanced multimedia application can be successfully synchronized with other media objects. Six smell categories are selected in the test to cover both positive (or pleasant) and negative (or unpleasant) smells: flowery, foul, fruity, burned, resinous, and spicy. This section presents an investigation of user perception of mulsemedia sequences which include haptic and air-flow components. This complements the study of olfaction-enhanced multimedia presented in [Ghinea and Ademoye, 2012]. A subjective test-bed was set up and participants were invited to have their experience with mulsemedia sequences assessed. The multimedia sequences, equipment, and software used for the test-bed are introduced next.

\subsection{Multimedia Sequences}

12 video clips are selected from two movies "Back To The Future" and "Jurassic Park" (i.e. 6 video clips from each movie) in order to ensure content diversity. The two movies "Jurassic Park" and "Back To The Future" contain all of the sensory media types (i.e. air-flow, olfaction, haptic) needed for the subjective test. Each movie has three episodes and lasts for up to five hours, providing plenty of sequences for the subjective tests. All video clips were MPEG-4 encoded and have the same settings: a resolution of $1280 \times 720$ pixels, frame rate is $30 \mathrm{fps}$, and an average bit-rate of $2500 \mathrm{Kbps}$. Both haptic and air-flow sensorial components were integrated and synchronized with the two movies. Each of two components is configured at three intensities levels (i.e. strong, medium, weak), as in the classification suggested in section 3.3. Therefore, for each movie, there are 6 video clips delivering strong, medium, and weak haptic effects, and strong, medium, and weak air-flow effects, respectively. Figure 4 shows a sample video frame computed from each video clip (<<Back To The Future >>). The video clips are 15 seconds long each.

\subsection{Equipment and Software}

Additional equipment and software are required to integrate the multiple sensorial effects into the multimedia sequences and display these sequences to users. Figure 5 shows the equipment and software used. Haptic 


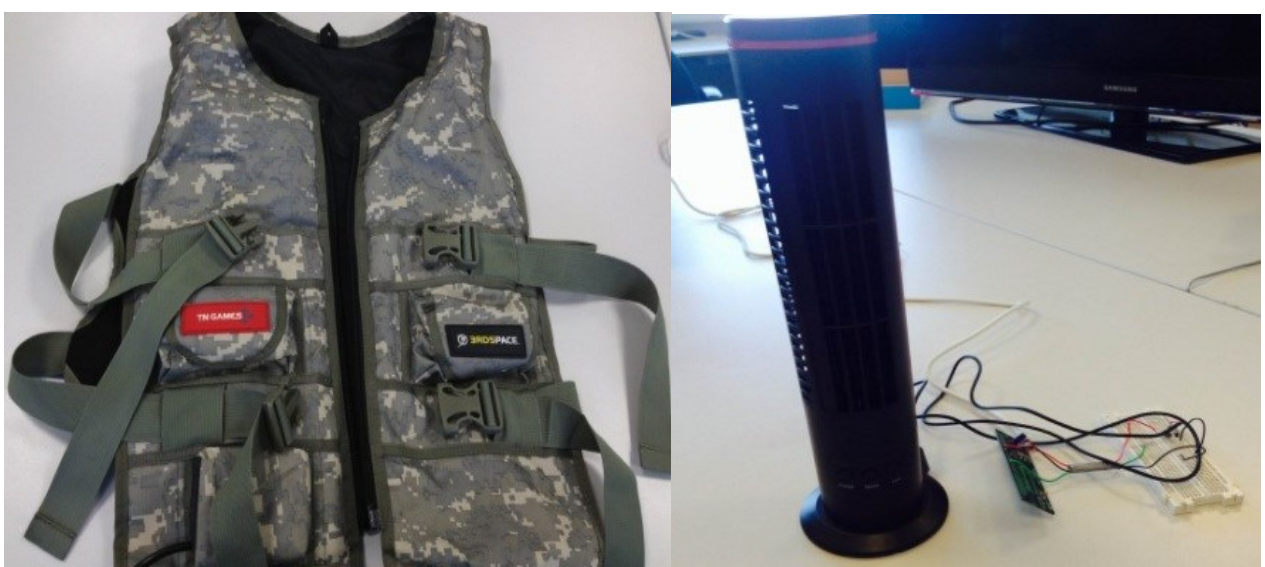

(A) Haptic vest

(B) USB Fan

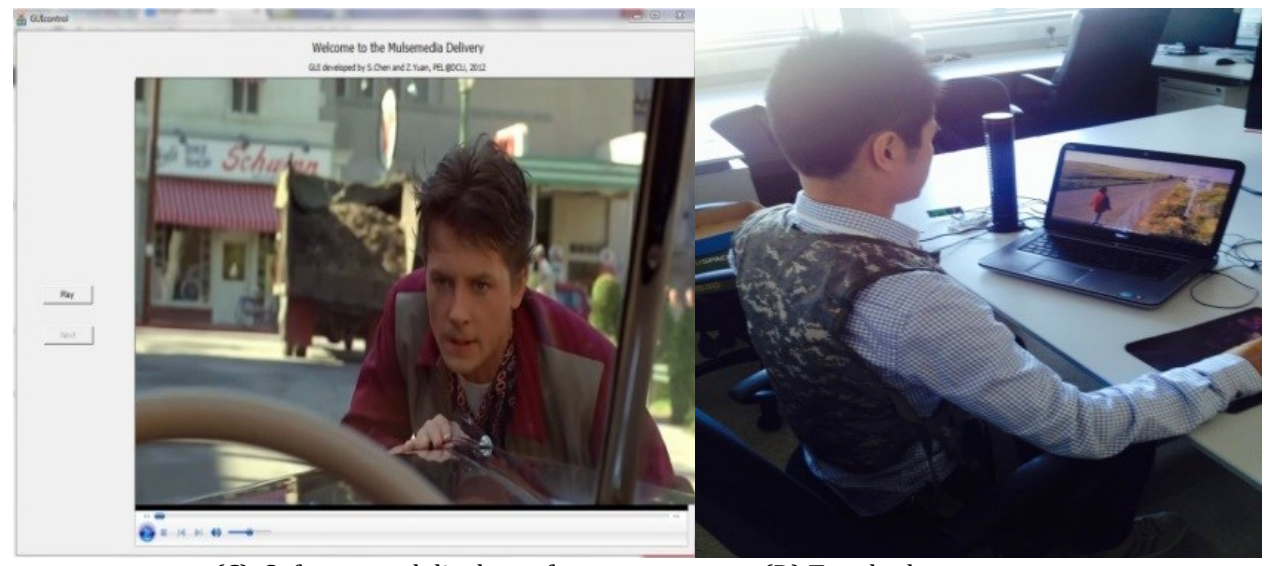

(C) Software and display software

(D) Test-bed

Fig. 5. Equipment and software used in the mulsemedia movie sequence

effects are generated by a vibration vest, as shown in Figure 5 (a), which is available from TN Games ${ }^{1}$. The vest provides fully programmable control of the haptic effects in terms of intensity levels, types, and duration. The vest simulates the precise direction and force of on-screen actions (e.g. bullet firings, explosions, environmental effects, etc.) via 8 pneumatic actuators (i.e. two on the chest, two on the stomach and four on the back) which generate pushes toward the user's body. Figure 5 (b) shows the USB fan that provides the airflow effects. The fan can generate strong, medium, and weak levels of air-flow and the on/off functionality is controlled by a Visual Basic program using USBmicro $2002^{2}$. Figure 5 (c) presents the graphical user interface of the developed software, which controls the haptic and air-flow generating devices and displays the movie clips for the users. According to the content scenario, the haptic and air-flow effects are manually synchronized to the associate multimedia clips by setting the start and end timestamps to activate and stop the vest vibration and the USB fan. The intensity of the air-flow is also manually adjusted based on the content scenario described in Table 4. For instance, a strong intensity air-flow is needed for simulating a hurricane, a medium intensity air-flow is appropriate for windy weather, and a weak intensity air-flow is used for a gentle breeze such as a subway train passing by.

\subsection{Subjective Test-bed Development}

The subjective test-bed, as shown in Figure 5 (d), was built in a dedicated and separate lab room (to minimize any potential disturbance) in the Performance Engineering Lab at Dublin City University, Ireland, where the tests took place. The testing environment was set up according to the recommendations of the ITU-T R. P.911 [Anon n.d.]. The users wore the haptic vest and sat in front of the 23inches LCD screen. The USB fan was placed

\footnotetext{
${ }^{1}$ TN Games, http://tngames.com/

${ }^{2}$ USBmicro, http://www.usbmicro.com/
} 
at a distance of 12 inches from the users. The room windows were closed to avoid any possible interference of both atmospheric air movement (wind) and noise affecting the testing.

\subsection{Participants}

18 users (11 males and 7 females) from various backgrounds (e.g. students, engineers, scientists, etc.) and various areas of major interest (e.g. computer science, engineering, biology, finance, etc.), between 20-36 years of age range (average age 27.6 years) took part in these tests. The instructions given to the participants and the personal information form to be filled are provided in appendix B.

\subsection{Method}

Of the 18 users, 9 participants were randomly selected to watch the "Jurassic Park" sequences with haptic effects and "Back To The Future" clips with air-flow effects. Conversely, the remaining 9 users watched the "Jurassic Park" sequences with associated air-flow effects and "Back To The Future" clips with haptic effects. Each movie-effect combination includes three intensity levels, e.g. strong, medium, and weak. Each user thus watches 6 video clips 3 clips from "Back To The Future" and 3 clips from "Jurassic Park"; for a particular movie all the intensity levels - strong, medium and weak - of the particular sensorial effect associated with the movie were experienced); on the other hand, each video clip is seen by 9 different users. So as to prevent order effects, the presentation order of the various clips was randomized in turn for all users participating in the experiment, as recommended in [Ghinea and Thomas, 2005].

All users were asked to complete a quick pre-test in order to get familiar with the testing process. After watching each video clip, each user then completed a questionnaire in which $\mathrm{s} / \mathrm{he}$ was asked to comment on his/her experience in relation to the mulsemedia sequence. The QoE evaluation questionnaire employed is shown in appendix B. This includes statements as follows:

(1) "The haptic/air-flow effect enhances the sense of reality."

(2) "The haptic/air-flow effect is distracting."

(3) "The haptic/air-flow effect is annoying."

(4) "The haptic/air-flow effect experienced is $\{$ Too Weak/Weak/Fine/Strong/Too Strong $\}$ "

(5) "The multi-sensorial movie is enjoyable."

It took around 6 minutes for each user to complete each test.

\section{RESULTS ANALYSIS}

The results of the user subjective tests involving mulsemedia sequences were collected from the test questionnaires and are analyzed in this section. Section 5.1 analyses the reliability of the subjects input. Section 5.2 analyses the results of haptic and air-flow effects.

\subsection{Reliability Analysis of the Subjects Input}

The subjective test results are measured in terms of internal reliability, which reflects the extent to which participants are consistent in their ratings over different questions. Internal reliability is typically computed by the Cronbach alpha coefficient $(\alpha)$ [Nunnaly, 1978]. There are 108 copies of questions being responded to. Answers for each question include five options: Strongly Disagree, Disagree, Neutral, Agree, and Strongly Agree, which, for analysis purposes, are mapped to the numeric scale: $1,2,3,4,5$, respectively. The obtained results are reliable if variables generated from a set of questions return a stable response. The Cronbach alpha coefficient ranges in value from 0 to 1 ; the higher the score, the more reliable the generated scale is. It is indicated that $\alpha=0.7$ is an acceptable reliability coefficient [Nunnaly, 1978]. IBM SPSS predictive analytics software ${ }^{3}$ was used to calculate Cronbach's alpha $(\alpha)$ over the subjective test results in this paper, in which $\alpha$ equals 0.84 , indicating reliable internal consistency of the subjects' input. However, caution should be taken when interpreting self-report measures [Donaldson and. Grant-Vallone, 2002].

\subsection{Impact of Haptic/Air-flow Intensities Levels on User QoE}

In this section, user experiences of haptic and air-flow effects with the different levels are analyzed following user questionnaire responses.

\footnotetext{
${ }^{3}$ IBM SPSS, http://www-01.ibm.com/software/analytics/spss/
} 
Table 5 User Response to the Intensity Levels of Haptic and Air-flow

\begin{tabular}{|c|c|c|c|c|c|}
\hline & \multicolumn{5}{|c|}{ User perception of the intensity of the haptic effect } \\
\hline PERCEPTION & Too Weak & Weak & Fine & Strong & Too Strong \\
\hline COUNT & 1 & 14 & 33 & 4 & 2 \\
\hline PERCENTAGE & $1.9 \%$ & $12.9 \%$ & $74.1 \%$ & $7.4 \%$ & $3.7 \%$ \\
\hline & \multicolumn{5}{|c|}{ User perception of the intensity of the air-flow effect } \\
\hline PERCEPTION & Too Weak & Weak & Fine & Strong & Too Strong \\
\hline COUNT & 4 & 13 & 29 & 7 & 1 \\
\hline PERCENTAGE & $7.4 \%$ & $16.1 \%$ & $71.7 \%$ & $3.0 \%$ & $1.8 \%$ \\
\hline
\end{tabular}

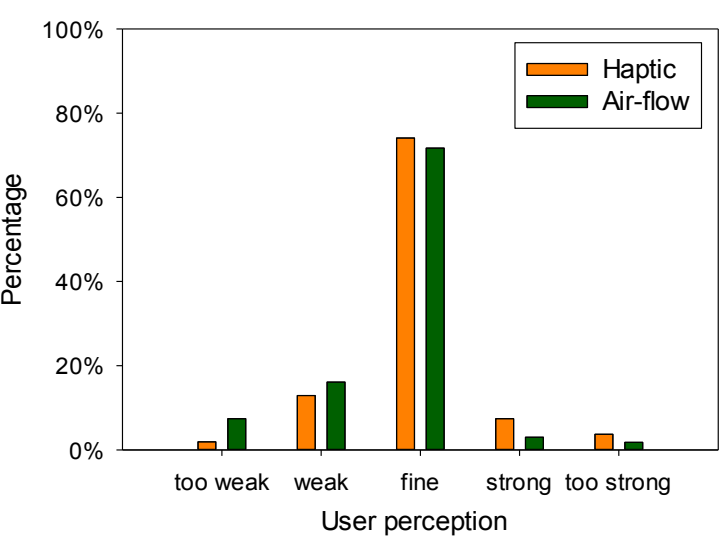

Fig. 6. User Response to the Intensity Levels of Haptic and Air-flow

Table 6 User Perception on the Intensity Levels of Haptic and Air-flow

\begin{tabular}{|c|c|c|c|c|c|c|}
\hline \multirow{2}{*}{} & \multicolumn{5}{|c|}{ The multi-sensorial movie is enjoyable } \\
\cline { 3 - 7 } & $\begin{array}{c}\text { Strongly } \\
\text { Disagree }\end{array}$ & Disagree & Neutral & \multirow{2}{*}{ Agree } & Strongly Agree \\
\hline \multirow{3}{*}{ HAPTIC } & Strong & $6.1 \%$ & $10.3 \%$ & $15 \%$ & $51.7 \%$ & $16.9 \%$ \\
\cline { 2 - 7 } & Medium & $7.2 \%$ & $12.5 \%$ & $16.8 \%$ & $47.8 \%$ & $15.7 \%$ \\
\cline { 2 - 7 } & Weak & $8.6 \%$ & $14.3 \%$ & $17.7 \%$ & $47.8 \%$ & $11.6 \%$ \\
\hline \multirow{2}{*}{ AIR- } & Strong & $5.8 \%$ & $10.7 \%$ & $12.5 \%$ & $48.3 \%$ & $23.7 \%$ \\
\cline { 2 - 7 } FLOW & Medium & $7.8 \%$ & $13.2 \%$ & $18.1 \%$ & $40.4 \%$ & $20.5 \%$ \\
\cline { 2 - 7 } & Weak & $9.2 \%$ & $15.3 \%$ & $17.5 \%$ & $35.6 \%$ & $12.4 \%$ \\
\hline
\end{tabular}

\subsubsection{User Perceived Sensorial Intensities}

In order to investigate users' feedback in respect of the different intensities levels of haptic and air-flow effects experienced, users were asked to indicate their opinion in respect of the below statement (see appendix B.2 and appendix B.3):

User perception of the intensity of the haptic/air-flow effect is: \{Too Weak, Weak, Fine, Strong, Too Strong\}.

Each user indicated one of five responses following his/her perceived degree of match between the movie content and the provided intensity level of the sensorial effects. Table 5 and Figure 6 present the user responses to different intensity levels of haptic and air-flow experience in the mulsemedia clips. By analyzing Table 5 and Figure $6,74.1 \%$ and $71.7 \%$ of the users consider the intensities associated with the air-flow and haptic sensorial effects levels, respectively, to be Fine. Less than $10 \%$ of users consider the haptic and air-flow effects provided are either Too weak or Too strong. Consequently, it can be concluded that the different intensities levels provided in the subjective tests performed have satisfied the large majority of the participants.

\subsubsection{Impact of Sensorial Intensities Levels on User Enjoyment}

In order to investigate the impact of different intensities levels of haptic and air-flow sensorial effects on user enjoyment, participants were asked to answer the following question (see appendix B.2 and appendix B.3):

The multi-sensorial movie is enjoyable: \{Strongly Disagree, Disagree, Neutral, Agree, Strongly Agree\} 

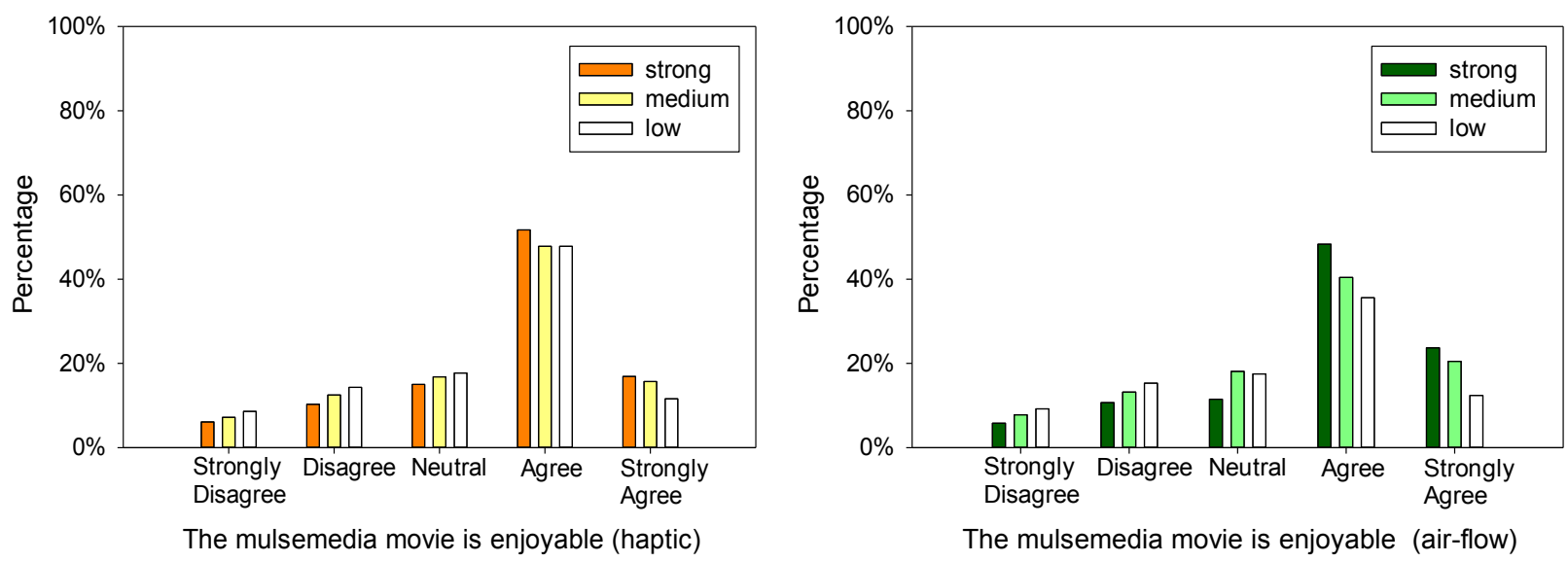

Fig. 7. User Perception on the Intensity Levels of Haptic and Air-flow

Table 7 Impact of Haptic Effect on the User-Perceived Experience

\begin{tabular}{|c|c|c|c|c|c|}
\hline QUESTION 1 & \multicolumn{5}{|c|}{ The haptic effect enhances the sense of reality } \\
\hline PERCEPTION & Strongly Disagree & Disagree & Neutral & Agree & Strongly Agree \\
\hline COUNT & 1 & 9 & 16 & 22 & 6 \\
\hline PERCENTAGE & $1.9 \%$ & $10.7 \%$ & $19.6 \%$ & $50.7 \%$ & $16.1 \%$ \\
\hline QUESTION 2 & \multicolumn{5}{|c|}{ The haptic effect is distracting } \\
\hline PERCEPTION & Strongly Disagree & Disagree & Neutral & Agree & Strongly Agree \\
\hline COUNT & 11 & 17 & 16 & 9 & 1 \\
\hline PERCENTAGE & $23.3 \%$ & $41.5 \%$ & $26.6 \%$ & $6.7 \%$ & $1.9 \%$ \\
\hline QUESTION 3 & \multicolumn{7}{|c|}{ The haptic effect is annoying } \\
\hline PERCEPTION & Strongly Disagree & Disagree & Neutral & Agree & Strongly Agree \\
\hline COUNT & 22 & 22 & 6 & 4 & 0 \\
\hline PERCENTAGE & $40.7 \%$ & $40.7 \%$ & $11.1 \%$ & $7.5 \%$ & $0.0 \%$ \\
\hline QUESTION 4 & \multicolumn{7}{|c|}{ The multi-sensorial movie is enjoyable } \\
\hline PERCEPTION & Strongly Disagree & Disagree & Neutral & Agree & Strongly Agree \\
\hline COUNT & 0 & 11 & 16 & 17 & 10 \\
\hline PERCENTAGE & $0.0 \%$ & $8.4 \%$ & $14.6 \%$ & $49.5 \%$ & $27.5 \%$ \\
\hline
\end{tabular}

One of five options is selected by each user to indicate his/her enjoyment levels when being presented with mulsemedia associated with haptic and air-flow components at different intensities levels. Results are depicted in Table 6 and Figure 7. By adding the number of responses of Agree and Strongly Agree (i.e. those responses showing a positive disposition in respect of enjoying the mulsemedia experience), it can be concluded that all of the three intensity levels (i.e. strong, medium, and weak) for both haptic and air-flow provide high levels of satisfaction in terms of user enjoyment. For instance, in the case of the haptic effect, the combined values of Agree and Strongly Agree for strong, medium, and weak intensity levels equal 68.6\%, 63.5\%, 59.4\%, respectively and in the case of the air-flow effect, the combined values of Agree and Strongly Agree for strong, medium, and weak intensity levels equal $72.0 \%, 60.9 \%, 48.0 \%$, respectively.

\subsubsection{Impact of Haptic/Air-flow Integrated Mulsemedia on the User-Perceived Experience}

This section presents the result analysis of the impact of mulsemedia sequences on user perceived satisfaction. The influence of mulsemedia on user perceptions is ascertained according to user opinions in respect of the following statements (see appendix B.2 and appendix B.3):

(1) User-perceived experience of the sense of reality of the sensorial effects

(2) User-perceived experience of the distraction of the sensorial effects

(3) User-perceived experience of the annoyance of the sensorial effects

(4) Overall user-perceived experience of the enjoyment of the sensorial effects 


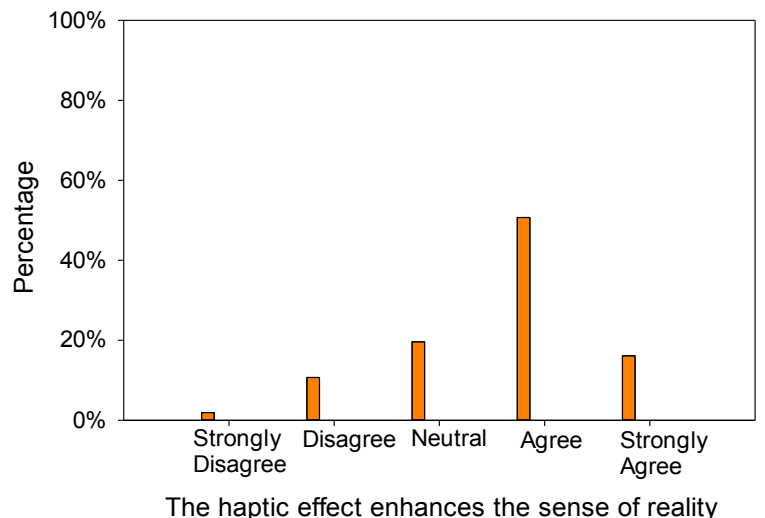

(A) The haptic effect enhances the sense of reality

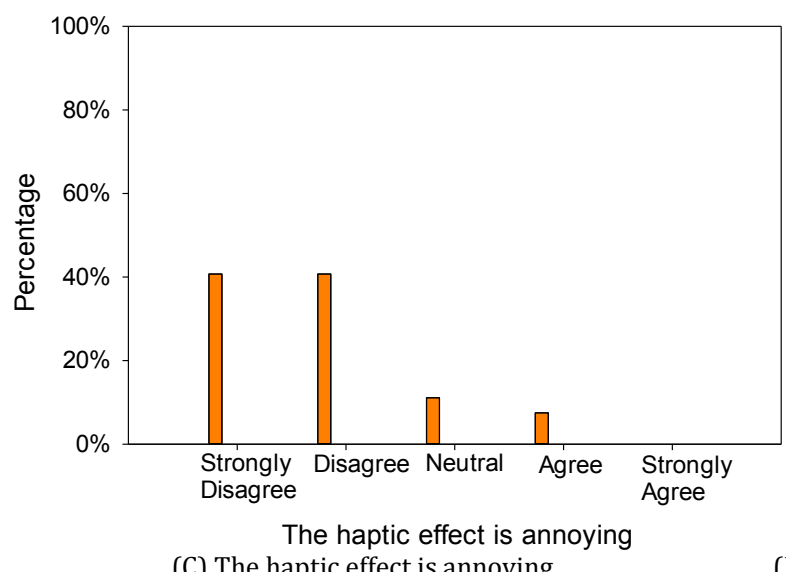

(C) The haptic effect is annoying

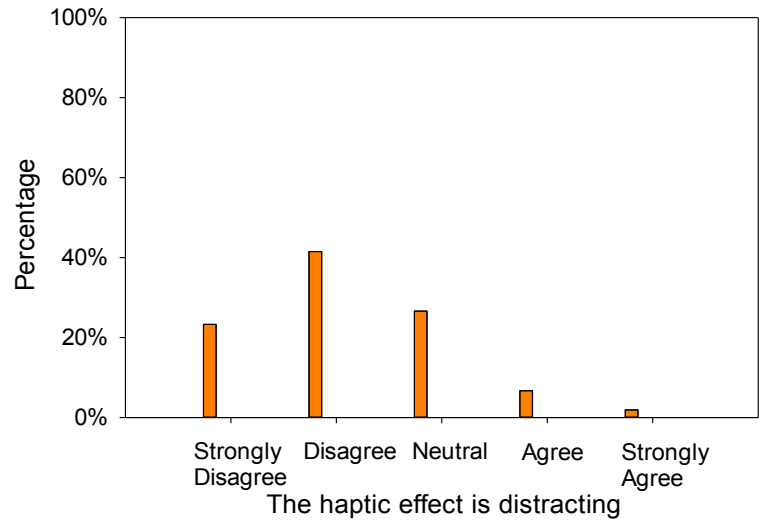

(B) The haptic effect is distracting

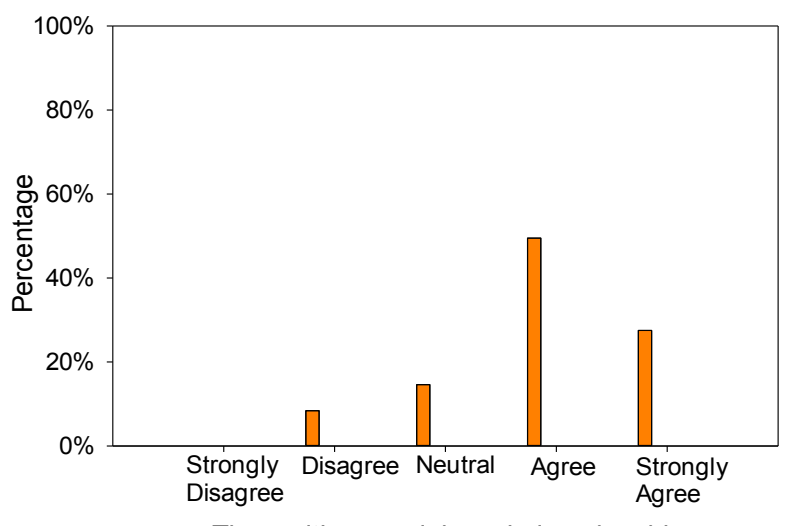

(D) The mulsemedia is enjoyable

Fig. 8. Impact of Haptic Effect on the User-Perceived Experience

For a particular effect (i.e. haptic or air-flow), each user watched three video clips each associated with one of three intensities levels (i.e. strong, medium, and weak). After the mulsemedia presentation, each participant was asked to respond to the four statements above using one of the five agreement levels: Strongly Disagree, Disagree, Neutral, Agree, and Strongly Agree. The breakdown of responses thus obtained is given in Table 7 and Table 8 and illustrated in Figure 8 and Figure 9. Next, the users' feedback on the four statements is analyzed in more detail.

Impact of haptic and air-flow effects on the sense of reality of the mulsemedia. To study the influence of sensorial effects on the perceived sense of reality of the mulsemedia sequences, users' agreement levels are collected, as shown in Figure 8 (A) and Figure 9 (A). The percentage of users who Agree and Strongly agree that the haptic effect enhances the sense of reality reaches $50.7 \%$ and $16.1 \%$, respectively. Additionally, the percentages of users who agreed and strongly agreed that the air-flow effect enhances the sense of reality are $45.2 \%$ and $16.7 \%$, respectively. It can be concluded that, the majority of users consider that both haptic and air-flow effects in mulsemedia sequences improve the sense of reality. This is in keeping with previous results on mulsemedia research dealing with olfactory effects [Ghinea and Ademoye, 2012]

Impact of distraction caused by haptic and air-flow effects of the mulsemedia. Users' responses indicating their level of agreement or disagreement are analyzed from the questionnaires, as illustrated in Figure 8 (B) and Figure 9 (B). Results show that $8.6 \%$ and $3.7 \%$ of users indicated that haptic and air-flow effects distract them, respectively. In conclusion, the majority of users consider that haptic and air-flow effects in mulsemedia sequences are not distracting. Again, this is in a similar vein to user experience research dealing with olfaction-enhanced mulsemedia [Ghinea and Ademoye, 2012]. 
Table 8 Impact of Air-flow Effect on User-Perceived Experience

\begin{tabular}{|c|c|c|c|c|c|}
\hline QUESTION 1 & \multicolumn{5}{|c|}{ The air-flow effect enhances the sense of reality } \\
\hline PERCEPTION & Strongly Disagree & Disagree & Neutral & Agree & Strongly Agree \\
\hline COUNT & 1 & 6 & 19 & 19 & 9 \\
\hline PERCENTAGE & $1.9 \%$ & $6.1 \%$ & $30.2 \%$ & $45.2 \%$ & $16.7 \%$ \\
\hline QUESTION 2 & \multicolumn{5}{|c|}{ The air-flow effect is distracting } \\
\hline PERCEPTION & Strongly Disagree & Disagree & Neutral & Agree & Strongly Agree \\
\hline COUNT & 27 & 20 & 5 & 2 & 0 \\
\hline PERCENTAGE & $50.0 \%$ & $37.0 \%$ & $9.3 \%$ & $3.7 \%$ & $0.0 \%$ \\
\hline QUESTION 3 & \multicolumn{7}{|c|}{ The air-flow effect is annoying } \\
\hline PERCEPTION & Strongly Disagree & Disagree & Neutral & Agree & Strongly Agree \\
\hline COUNT & 30 & 20 & 4 & 0 & 0 \\
\hline PERCENTAGE & $55.6 \%$ & $35.2 \%$ & $7.4 \%$ & $1.8 \%$ & $0.0 \%$ \\
\hline QUESTION 4 & \multicolumn{7}{|c|}{ The multi-sensorial movie is enjoyable } \\
\hline PERCEPTION & Strongly Disagree & Disagree & Neutral & Agree & Strongly Agree \\
\hline COUNT & 0 & 2 & 27 & 13 & 12 \\
\hline PERCENTAGE & $0.0 \%$ & $3.6 \%$ & $24.1 \%$ & $47.1 \%$ & $25.2 \%$ \\
\hline
\end{tabular}

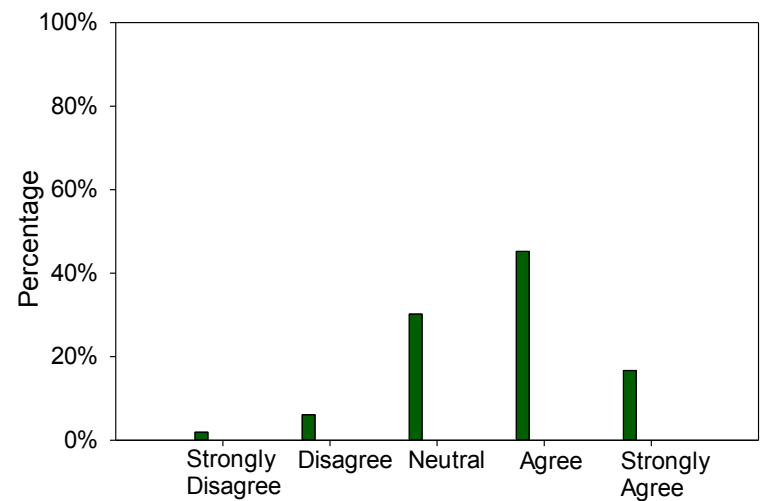

(A) The air-flow effect enhances the sense of reality

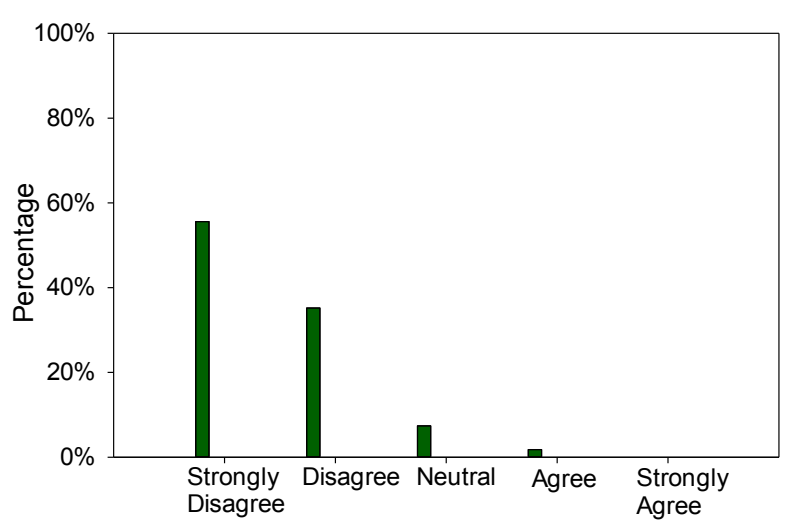

(C) The air-flow effect is annoying

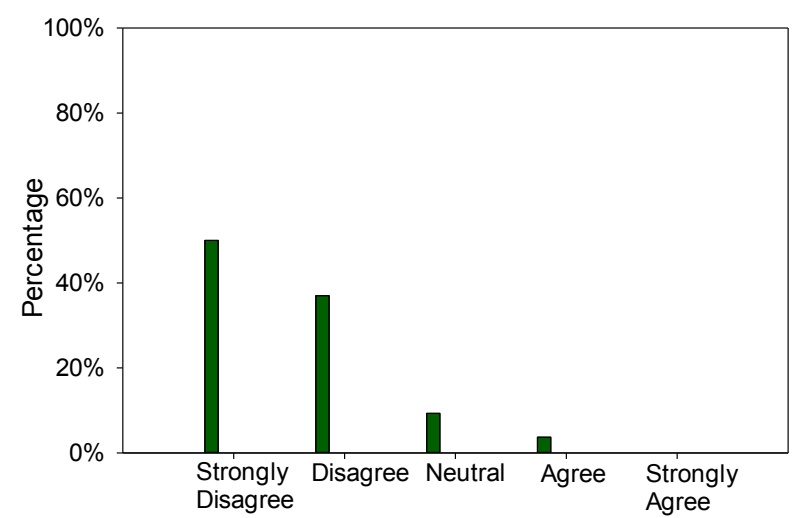

(B) The air-flow effect is distracting

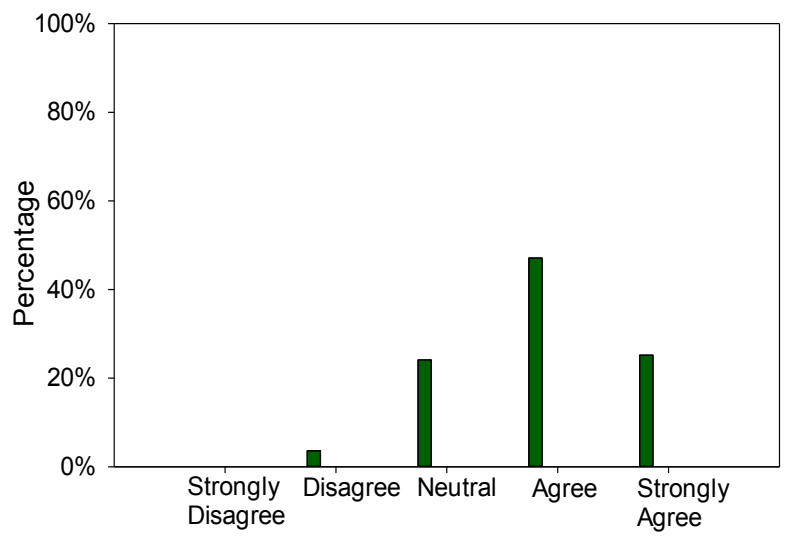

(D) The mulsemedia is enjoyable

Fig. 9. Impact of Air-flow Effect on the User-Perceived Experience

Impact of annoyance caused by haptic and air-flow effects of the mulsemedia. In order to measure the impact of haptic and air-flow effects on the annoyance levels, users' responses to the questionnaire statement "The haptic/air-flow effect is annoying" are analyzed and illustrated in Figure 8 (C) and Figure 9 (C). In this respect, the results obtained reveal that the percentage of users who consider that haptic and air-flow effects are 
annoying reaches $7.5 \%$ and $1.8 \%$, respectively, in terms of the combined number of Agree and Strongly Agree answers. It is concluded that both haptic and air-flow effects in mulsemedia do not result in annoyance of mulsemedia users. Similar results have been obtained in respect of olfactory effects [Ghinea and Ademoye, 2012].

Impact of mulsemedia on user enjoyment. User enjoyment [ETSI 2009] measures both the process and outcomes of communication based on subjective psychological measures of using an ICT service or product. User enjoyment is a key indicator of quality of experience. The impact of mulsemedia presentation on the perceived level of user enjoyment is also considered. To this end, results obtained from the questionnaire statement "The multi-sensorial movie is enjoyable" are analyzed and illustrated in Figure 8 (D) and Figure 9 (D). It is shown that the percentage of users which consider mulsemedia enjoyable to be $77 \%$ and $72.3 \%$ for haptic and air-flow, respectively. In conclusion, most users tend to agree that both haptic and air-flow effects occurring as part of a mulsemedia presentation result in an enjoyable experience. It is reassuring that this also follows the general trend of mulsemedia QoE results previously reported for olfaction-enhanced mulsemedia [Ghinea and Ademoye, 2012].

\section{CONCLUSION}

User acceptance of mulsemedia is key to its future. Whilst the earliest identifiable mulsemedia applications were created over half a century ago, arguably one of the inhibitors of their success has been the lack of user take-up. User experience is key to user take-up - a good user experience will generally lead to good take-up and demand; conversely, a negative one - or even a novel one insufficiently understood - will dampen take-up.

In the 50 years or so since Heilig introduced the Sensorama, our understanding of and the importance we attach to the user experience has increased and evolved. In the digital multimedia age, quality of experience is the way through which researchers seek to better comprehend the user-side of digital experiences. Accordingly, this paper introduces the investigation of user quality of experience of mulsemedia applications. Categories of the mulsemedia applications are firstly introduced by analyzing users' preferences of mulsemedia based on on-line questionnaires. It is shown that olfaction, haptic and air-flow are the most expected human sensorial effects that should occur in mulsemedia content. Additionally, users expect to have different responses to the variable types of olfaction and different intensity levels of haptic and air-flow effects. Results reveal that 1 ) in the case of olfaction, the user preference level descends in the sequence of positive, neutral, and negative olfaction types; 2 ) in the case of haptic and air-flow, the user preference level descends in the sequence of strong, medium, and weak intensity levels.

Extensive subjective tests have been conducted to study the impact of haptic and air-flow on user quality of experience in terms of five aspects: impact on sense of reality, impact on distraction, impact on annoyance, user responses to the intensity levels, and user enjoyment levels. In general, the vast majority of users polled (roughly 70\% in both cases) consider that both haptic and air-flow effects in mulsemedia enhances the sense of reality and user enjoyment levels. In contrast, relatively few users experienced any distraction and/or annoyance as a result of haptic and air-flow effects, with less than $4 \%$ of users in these categories. In addition, results show that users show no significant enhanced or reduced perceptions when switching between the intensity levels of haptic and users indicate significant reduced perception levels (i.e. up to 47.7\%) when reducing the intensity level of air-flow in the mulsemedia.

Of course, it may well be that mulsemedia is a fad and that the tested users just appreciate the experience due to the novelty factor involved. In order to confirm (or reject) this hypothesis, further work must be done, employing methods such as the repeated evaluation technique [Carbon and Leder, 2005] or based on the procedure described by [Jakesch et al. 2011], specifically tailored to novel product evaluation in the context of multisensory environments. Both represent highly worthwhile and interesting future pursuits.

A higher number of experimental subjects would result in more accurate results. However, subjective testing is time and cost consuming. The trade-off between the performance and experimental expense should be considered. In our paper, 54 participants completed the online questionnaires and 18 users were invited to watch 12 video clips from two different movies. Each user submitted 6 copies of questionnaires on their perceived experience and in total 108 copies of questionnaires were received. Based on our previous experiences [Ghinea and Ademoye, 2010a, 2012; Murray et al., 2013; 2014] in evaluating user QoE in mulsemedia applications, the selected amount of experimental subjects can provide a high accuracy of results with limited costs. However, caution should be taken when interpreting self-report measures [Donaldson and Grant-Vallone, 2002]. 
Implementing mulsemedia applications have some practical limitations - all of which represent challenges for future research pursuits. First, the synchronization between sensorial effects and video content should be carefully designed. Due to the variable conditions (i.e. delay, jitter, etc) of IP networks, out-of-synchronization effects cannot be avoided. However, as remarked previously in [Ghinea and Ademoye 2010a] due to the lingering tendency of olfactory stimuli, traditional methods which take care of such network-introduced artefacts, such as buffering and adaptive playouts, are ineffective here; this also applies to other types of mulsemedia such as air-flow and gustatory effects, and future work should focus on solving this challenge. Moreover, any such endeavor should of necessity look at how this can be managed with a minimum of detrimental impact on user QoE. Second, advanced sensorial presentation equipment (such as haptic generators, air-flow generators, etc.) can be adopted to further enhance sense of reality. For instance, other than the haptic vest used in this paper, devices such as haptic chairs and/or robotic haptic systems can provide a wider spectrum of haptic effects; air-flow generators can output air with different temperature and humidity, whilst an advanced olfaction dispenser can provide dozens of flavor types.

Finally, we hope that the results and test-bed development that have been described in this study can provide a starting point in the design of an advanced solution for mulsemedia content delivery. As mentioned above, the impact of synchronization between sensorial media and video content on user QoE is expected to be studied in the future based on the test-bed presented in this paper. Media service providers can also optimize the delivery solution for disseminating mulsemedia content based on the research found in this paper. For instance, adaptation strategies could be formulated for mulsemedia content according to user preferences and network conditions in order to achieve high user QoE. Last but not least, the results described in this paper could also benefit immersive communications in services such as mulsemedia-enhanced interactive video conferencing, online gaming, and content environmental-aware e-learning systems, to name but a few potential applications.

\section{ACKNOWLEDGEMENT}

The authors would like to acknowledge the support from Enterprise Ireland and LM Ericsson under the Innovation Partnership Programme (IP/2011/0135) in collaboration with Dublin City University, Ireland. The support from China Scholarship Council is also acknowledged.

\section{REFERENCES}

Z. Yuan, G. Ghinea, G.-M. Muntean, "Quality of Experience Study for Multiple Sensorial Media Delivery", accepted by IEEE International Wireless Communications and Mobile Computing Conference (IEEE IWCMC), Nicosia, Cyprus, Aug. 2014.

Adam Bodnar, R.C., 2014, AROMA: Ambient awaReness through Olfaction in a Messaging Application - Does Olfactory Notification Make "Scents"?, In Proceedings of ACM International Conference on Multimodal Interfaces.

Anon, P.911 : Subjective audiovisual quality assessment methods for multimedia applications.

Apostolopoulos, J.G., Chou, P.A., Culbertson, B., Kalker, T., Trott, M.D. and Wee, S., 2012. The Road to Immersive Communication. Proceedings of the IEEE, 100(4), pp.974-990.

Blakowski, G. and Steinmetz, R. 1996, A Media Synchronisation Survey: Reference Model, Specification, and Case Studies, IEEE Journal on Selected Areas in Communications, 14( 1) pp. 5-35.

Carbon, C. C. and Leder, H. 2005. The repeated evaluation technique (RET). A method to capture dynamic effects of innovativeness and attractiveness. Applied Cognitive Psychology, 19(5), pp. 587-601.

Cater, J.P. 1992. The Nose Have It! Letters to the Editor, Presence, 1(4), pp. 493-494.

Dinh, H.Q., Walker, N., Hodges, L.F., Song, C. \& Kobayashi, A. 1999, Evaluating the importance of multi-sensory input on memory and the sense of presence in virtual environments, Proceedings - Virtual Reality Annual International Symposium, pp. 222-228.

Donaldson S. I. and Grant-Vallone, E. J. 2002. Understanding self-report bias in organizational behavior research, Journal of Business and Psychology, 17(2) pp. 245-260. 
ETSI TR 102643 V1.0.1, 2009 "Human Factors (HF);Quality of Experience (QoE) requirements for real-time communication services," technical report.

Ghinea, G., Gulliver, S.R., and Andres, F., 2011, Multiple Sensorial Media Advances and Applications: New Developments in MulSeMedia, IGI Global.

Ghinea, G. and Ademoye, O.A., 2010a. Perceived Synchronization of Olfactory Multimedia. IEEE Transactions on Systems, Man and Cybernetics, Part A: Systems and Humans, 40(4), pp. $657-663$.

Ghinea, G., and Ademoye, O.A., 2010b. A user perspective of olfaction-enhanced mulsemedia. In Proceedings of the International Conference on Management of Emergent Digital EcoSystems, pp. 277-280.

Ghinea, G. and Ademoye, O.A, 2012 "The Sweet Smell of Success: Enhancing Multimedia Applications with Olfaction", ACM Transactions on Multimedia Computing, Communications and Applications, 8(1), Article 2

Ghinea, G., and Thomas, J.P. 2005, Quality of Perception: User Quality of Service in Multimedia Presentations, IEEE Transactions on Multimedia, 7(4), pp. 786-789.

Heilig M. L. (1962), Sensorama Simulator, United States Patent Office (3,050,870); Patented August 28.

Jakesch, M., Zachhuber, M., Leder, H., Spingler, M., and Carbon, C. C. (2011). Scenario-based touching: On the influence of top-down processes on tactile and visual appreciation. Research in Engineering Design, 22, 143-152.

Ishibashi, Y., Kanbara, T., and Tasaka, S., Inter-stream synchronization between haptic media and voice in collaborative virtual environments, in Proceedings of the 12th annual ACM international conference on Multimedia, 2004, pp. 604-611

Kaye, J. N. 2001. Symbolic olfactory display. M.S. thesis, Massachusetts Institute of Technology. http://alumni.media.mit.edu/ jofish/thesis/ [Accessed: March 10, 2014]

Kahol, K., Tripathi, P., Mcdaniel, T., Bratton, T., and Panchanathan, S., 2006, Modeling context in haptic perception, rendering, and visualization, ACM Transactions on Multimedia Computing, Communications and Applications, 2,(3), pp. 219-240.

Murray, N., Qiao, Y., Karunakar A K, Lee, B., and Muntean, G-M. 2013. "Subjective Evaluation of Olfactory and Visual Media Synchronization" In Proceedings of ACM Multimedia Systems Conference Feb 26 - March 1, Oslo, pp. 162-171.

Murray, N., Qiao, Y., Lee, B., and Muntean, G-M. 2014. User-profile-based perceived olfactory and visual media synchronization. ACM Transactions on Multimedia Computing, Communications and Applications, 10(1), Article 11, pp. 11:01-11:24

Nagle, H.T., Gutierrez-Osuna, R., and Schiffman, S.S., 1998, The How and Why of Electronic Noses, IEEE Spectrum, vol. 35, no. 9, pp. $22-31$.

NTT Communications (NTT Com) 2006, Movie Enhanced with Internet-based Fragrance System. Available: http://www.in70mm.com/news/2006/new_world/index.htm [Accessed: March 10, 2014].

Nunnaly, J. (1978). Psychometric theory. New York: McGraw-Hill.

Steinbach, E., Hirche, S., 2012, Ernst, M., Brandi, F., Chaudhari, R., Kammerl, J., and Vittorias, I., Haptic Communications, Proceedings of the IEEE, 100(4), pp. 937 -956.

Washburn, D.A., Jones, L.M., Satya, R.V., Bowers, C.A. and Cortes, A. 2003. Olfactory Use in Virtual Environment Training, Modelling and Simulation Magazine, 2(3). 


\section{Online Appendix to: User Quality of Experience of Mulsemedia Applications}

ZHENHUI YUAN Dublin City University

SHENGYANG CHEN Dublin City University

GHEORGHITA GHINEA, Brunel University

GABRIEL-MIRO MUNTEAN, Dublin City University

\section{A. ON-LINE SURVEY OF USER PREFERENCE OF MULSEMEDIA}

The questionnaire is designed including questions as follows.

1) GENDER*

() MALE ( ) FEMALE

2) $\mathrm{AGE}^{*}$

() UNDER 18 ( ) 18-24 () 25-34 ( ) 35-54 ( ) 55+

3) HOW OFTEN DO YOU WATCH MOVIES?*

( ) EVERY DAY ( ) OCCASIONALLY ( ) ONCE/WEEK ( ) ONCE/MONTH ( ) NEVER

4) PLEASE SELECT YOUR FAVORITE MOVIE GENRE.*

( ) ACTION ( ) ANIMATION ( ) ADVENTURE ( ) BIOGRAPHY ( ) COMEDY ( ) CRIME ( ) DRAMA ( ) FANTASY ( ) GAME-SHOW ( ) HISTORY ( ) HORROR ( ) MUSIC ( ) ROMANCE ( ) SCI-FI ( ) SPORT

( ) TALK-SHOW ( ) THRILLER ( ) WAR

5) I DO NOT LIKE EXPERIENCING HAPTIC SENSATIONS WHEN WATCHING MULTIMEDIA PRESENTATIONS*

( ) STRONGLY DISAGREE ( ) DISAGREE ( ) DISAGREE SOMEWHAT ( ) AGREE SOMEWHAT

() AGREE ( ) STRONGLY AGREE

6) I LIKE EXPERIENCING OLFACTORY SENSATIONS WHEN WATCHING MULTIMEDIA PRESENTATIONS*

() STRONGLY DISAGREE () DISAGREE () DISAGREE SOMEWHAT ( ) AGREE SOMEWHAT

() AGREE () STRONGLY AGREE

7) I LIKE EXPERIENCING AIR-FLOW SENSATIONS WHEN WATCHING MULTIMEDIA PRESENTATIONS*

( ) STRONGLY DISAGREE ( ) DISAGREE ( ) DISAGREE SOMEWHAT ( ) AGREE SOMEWHAT

() AGREE () STRONGLY AGREE

@ 2010 ACM 1544-3558/2010/05-ART1 $\$ 10.00$

DOI 10.1145/0000000.0000000 http://doi.acm.org/10.1145/0000000.0000000 
8) I DO NOT LIKE EXPERIENCING TASTE (GUSTATORY) SENSATIONS WHEN WATCHING MULTIMEDIA PRESENTATIONS*

() STRONGLY DISAGREE ( ) DISAGREE ( ) DISAGREE SOMEWHAT ( ) AGREE SOMEWHAT

() AGREE ( ) STRONGLY AGREE

9) I DO NOT LIKE EXPERIENCING TEMPERATURE EFFECTS WHEN WATCHING MULTIMEDIA PRESENTATIONS*

() STRONGLY DISAGREE ( ) DISAGREE () DISAGREE SOMEWHAT ( ) AGREE SOMEWHAT

() AGREE () STRONGLY AGREE

10) I LIKE EXPERIENCING HUMIDITY EFFECTS WHEN WATCHING MULTIMEDIA PRESENTATIONS*

() STRONGLY DISAGREE () DISAGREE () DISAGREE SOMEWHAT ( ) AGREE SOMEWHAT

() AGREE ( ) STRONGLY AGREE

IMAGINE THERE ARE THREE CONTEXTS IN A MOVIE SEQUENCE. PLEASE READ EACH CONTEXT AND ANSWER THE QUESTIONS.

CONTEXT 1: A COUPLE IS WALKING ON A BEACH, THE WIND BLOWS IN THEIR HAIR, AND THE OCEAN WAVES ARE BREAKING ON THE WET SAND. THE BOY STEPS ON A SAND CASTLE AND LOSES HIS BALANCE, GRABBING THE GIRL'S BODY.

11) PLEASE INDICATE IN CONTEXT 1, WHICH TYPE(S) OF SMELLS/AROMAS ARE YOU EXPECTING? (MULTIPLE CHOICE IS ALLOWED)*

[ ] FLOWER [] SMELL OF OCEAN [ ] BURNT [ ] RUBBISH [ ] FUEL [] ROTTEN BODY

[] NONE [ ] OTHER

12) PLEASE INDICATE IN CONTEXT 1, WHICH TYPE(S) OF HAPTIC EFFECTS ARE YOU EXPECTING?*

[] STRONG HAPTIC, E.G. HOLDING HAND, HUGGING, FALLING OVER

[] MEDIUM HAPTIC, E.G. HOLDING HAND, HUGGING, FALLING OVER

[ ] LIGHT HAPTIC, E.G. HOLDING HAND, HUGGING, FALLING OVER

[] NONE [] OTHER

13) PLEASE INDICATE IN CONTEXT 1, WHICH TYPE(S) OF AIR-FLOW EFFECTS ARE YOU EXPECTING?*

[] STRONG AIR-FLOW, E.G. OCEAN WIND

[ ] MEDIUM AIR-FLOW, E.G. OCEAN WIND

[] LIGHT AIR-FLOW, E.G. OCEAN WIND

[] NONE [] OTHER

CONTEXT 2: THE COUPLE GETS CLOSER AND THE BOY TALKS TO THE GIRL, THEN OFFERS HER A RED ROSE. THE GIRL TAKES IT AND SHE SMELLS IT DEEPLY, BEFORE THEY HUG EACH OTHER WITH PASSION. THEY COUPLE HUGG EACH OTHER DURING A MOMENT OF HAPPINESS, THEN THEY LOSE THE BALANCE AND FALL. THEY NOTICE A LARGE SEA CREATURE'S BODY LYING ON THE SAND IN FRONT OF THEM. 
14) PLEASE INDICATE IN CONTEXT 2, WHICH TYPE(S) OF SMELL ARE YOU EXPECTING?*

[ ] FLOWER [ ] SMELL OF OCEAN [] BURNT [] RUBBISH [ ] FUEL [] ROTTEN BODY

[] NONE [] OTHER

15) PLEASE INDICATE IN CONTEXT 2, WHICH TYPE(S) OF HAPTIC EFFECTS ARE YOU EXPECTING?*

[ ] STRONG HAPTIC, E.G. HOLDING HAND, HUGGING, FALLING OVER

[ ] MEDIUM HAPTIC, E.G. HOLDING HAND, HUGGING, FALLING OVER

[ ] LIGHT HAPTIC, E.G. HOLDING HAND, HUGGING, FALLING OVER

[] NONE [ ] OTHER

16) PLEASE INDICATE IN CONTEXT 2, WHICH TYPE(S) OF AIR-FLOW EFFECTS ARE YOU EXPECTING?*

[] STRONG AIR-FLOW, E.G. OCEAN WIND, AIR MOVEMENT

[] MEDIUM AIR-FLOW, E.G. OCEAN WIND, AIR MOVEMENT

[] LIGHT AIR-FLOW, E.G. OCEAN WIND, AIR MOVEMENT

[] NONE [] OTHER

CONTEXT 3: A LOUD SOUND AND STRONG WIND BLOWS WHEN A HELICOPTER LANDS ON THE BEACH IN THE COUPLE IMMEDIATE NEIGHBOURHOOD AND PEOPLE INVADE THE JUST-BEFORE-THAT EMPTY BEACH. THE COUPLE ARE INUNDATED BY A MIX OF SENSORIAL EFFECTS COMING FROM THE HELICOPTER: FUEL, NOISE AND AIR MOVEMENT, THE DECOMPOSING SEA CREATURE BODY: IMAGE AND SMELL, NATURE: OCEAN SMELL, WIND, BREAKING WAVE NOISE AND PEOPLE: VOICES, SWEET SMELL, COLOURFUL CLOTHING.

17) PLEASE INDICATE IN CONTEXT 3, WHICH TYPE(S) OF SMELL EFFECTS ARE YOU EXPECTING?*

[ ] FLOWER [ ] SMELL OF OCEAN [ ] BURNT [ ] RUBBISH [ ] FUEL [ ] ROTTEN BODY

[] NONE [] OTHER

18) PLEASE INDICATE IN CONTEXT 3, WHICH TYPE(S) OF HAPTIC EFFECTS ARE YOU EXPECTING?*

[] STRONG HAPTIC, E.G. HOLDING HAND, HUGGING, FALLING OVER

[ ] MEDIUM HAPTIC, E.G. HOLDING HAND, HUGGING, FALLING OVER

[ ] LIGHT HAPTIC, E.G. HOLDING HAND, HUGGING, FALLING OVER

[] NONE [] OTHER

19) PLEASE INDICATE IN CONTEXT 3, WHICH TYPE(S) OF AIR-FLOW EFFECTS ARE YOU EXPECTING?*

[] STRONG AIR-FLOW, E.G. OCEAN WIND, HELICOPTER COMING

[] MEDIUM AIR-FLOW, E.G. OCEAN WIND, HELICOPTER COMING

[] LIGHT AIR-FLOW, E.G. OCEAN WIND, HELICOPTER COMING

[] NONE [] OTHER 
20) PLEASE RATE THE SMELLS BASED ON YOUR OWN PREFERENCE*

$\begin{array}{lll}\text { BAD POOR FAIR } & \begin{array}{l}\text { VERY EXCELLENT } \\ \text { GOOD }\end{array}\end{array}$

$\begin{array}{llllll}\text { FLOWER } & - & - & - & - & - \\ \text { OCEAN } & - & - & - & - & - \\ \text { BURNT } & - & - & - & - & - \\ \text { FUEL } & - & - & - & - & - \\ \text { ROTTING BODY } & - & - & - & - & - \\ \text { RUBBISH } & - & - & - & - & -\end{array}$

\section{B. QUESTIONNAIRE DESIGN FOR SUBJECTIVE TEST}

The questionnaire is designed to be filled by users in subjective test.

B.1 Personal Information Form

Please check " $\sqrt{ }$ " for your choice

\begin{tabular}{|c|c|c|c|c|c|c|c|}
\hline Gender: & \multicolumn{3}{|l|}{ (A) Male } & \multicolumn{4}{|l|}{ (B) Female } \\
\hline Age: & \multicolumn{2}{|l|}{ (A) $<20$} & (B) $21-25$ & (C) $26-30$ & & \multicolumn{2}{|c|}{ (D) $>30$} \\
\hline $\begin{array}{l}\text { How often do you } \\
\text { watch movies? }\end{array}$ & \multicolumn{2}{|l|}{$\begin{array}{l}\text { (A) } \\
\text { Every day }\end{array}$} & $\begin{array}{l}\text { (B) } \\
\text { Twice/week }\end{array}$ & $\begin{array}{l}\text { (C) } \\
\text { Once/week }\end{array}$ & $\begin{array}{l}\text { (D) } \\
\text { Once/ }\end{array}$ & onth & \begin{tabular}{l|l} 
E) \\
Never
\end{tabular} \\
\hline $\begin{array}{l}\text { How familiar are } \\
\text { you with video } \\
\text { perception } \\
\text { assessment? }\end{array}$ & \multicolumn{3}{|c|}{ (A) Expert } & (B) Familiar & \multicolumn{3}{|c|}{ (C) Not familiar } \\
\hline $\begin{array}{l}\text { Which is your } \\
\text { favourite movie } \\
\text { type? }\end{array}$ & $\begin{array}{l}\text { (A) } \\
\text { Action }\end{array}$ & $\begin{array}{l}\text { (B) } \\
\text { Science } \\
\text { Fiction }\end{array}$ & $\begin{array}{l}\text { (C) } \\
\text { Comedy }\end{array}$ & $\begin{array}{l}\text { (D) } \\
\text { Cartoon }\end{array}$ & $\begin{array}{l}\text { (E) } \\
\text { Crime }\end{array}$ & $\begin{array}{l}\text { (F) } \\
\text { Art }\end{array}$ & $\begin{array}{l}\text { (G) } \\
\text { Other }\end{array}$ \\
\hline $\begin{array}{l}\text { Have you ever } \\
\text { experienced } \\
\text { watching movies } \\
\text { together with } \\
\text { sensorial devices } \\
\text { which provide } \\
\text { effects such as } \\
\text { olfaction, haptic } \\
\text { and air motion? }\end{array}$ & \multicolumn{3}{|l|}{ (A) Yes } & \multicolumn{4}{|l|}{ (B) No } \\
\hline
\end{tabular}


B.2 Please check the box as applicable.

1. The haptic effect enhances the sense of reality

\begin{tabular}{|c|c|c|c|c|}
\hline $\begin{array}{c}\text { Strongly } \\
\text { disagree }\end{array}$ & Disagree & Neutral & Agree & $\begin{array}{c}\text { Strongly } \\
\text { agree }\end{array}$ \\
\hline & & & & \\
\hline
\end{tabular}

2. The haptic effect is distracting

\begin{tabular}{|c|c|c|c|c|}
\hline $\begin{array}{c}\text { Strongly } \\
\text { disagree }\end{array}$ & Disagree & Neutral & Agree & $\begin{array}{c}\text { Strongly } \\
\text { agree }\end{array}$ \\
\hline & & & & \\
\hline
\end{tabular}

3. The haptic effect is annoying

\begin{tabular}{|c|c|c|c|c|}
\hline $\begin{array}{c}\text { Strongly } \\
\text { disagree }\end{array}$ & Disagree & Neutral & Agree & $\begin{array}{c}\text { Strongly } \\
\text { agree }\end{array}$ \\
\hline & & & & \\
\hline
\end{tabular}

4. User perception of the intensity of the haptic effect

\begin{tabular}{|c|c|c|c|c|}
\hline Too weak & Weak & Fine & Strong & Too strong \\
\hline & & & & \\
\hline
\end{tabular}

5. The multi-sensorial movie is enjoyable

\begin{tabular}{|c|c|c|c|c|}
\hline $\begin{array}{c}\text { Strongly } \\
\text { disagree }\end{array}$ & Disagree & Neutral & Agree & $\begin{array}{c}\text { Strongly } \\
\text { agree }\end{array}$ \\
\hline & & & & \\
\hline
\end{tabular}

B.3 Please check the box as applicable.

1. The air-flow effect enhances the sense of reality

\begin{tabular}{|c|c|c|c|c|}
\hline $\begin{array}{c}\text { Strongly } \\
\text { disagree }\end{array}$ & Disagree & Neutral & Agree & $\begin{array}{c}\text { Strongly } \\
\text { agree }\end{array}$ \\
\hline & & & & \\
\hline
\end{tabular}

2. The air-flow effect is distracting

\begin{tabular}{|c|c|c|c|c|}
\hline $\begin{array}{c}\text { Strongly } \\
\text { disagree }\end{array}$ & Disagree & Neutral & Agree & $\begin{array}{c}\text { Strongly } \\
\text { agree }\end{array}$ \\
\hline & & & & \\
\hline
\end{tabular}

3. The air-flow effect is annoying

\begin{tabular}{|c|c|c|c|c|}
\hline $\begin{array}{c}\text { Strongly } \\
\text { disagree }\end{array}$ & Disagree & Neutral & Agree & $\begin{array}{c}\text { Strongly } \\
\text { agree }\end{array}$ \\
\hline & & & & \\
\hline
\end{tabular}

4. User perception of the intensity of the air-flow effect

\begin{tabular}{|c|c|c|c|c|}
\hline Too weak & Weak & Fine & Strong & Too strong \\
\hline & & & & \\
\hline
\end{tabular}

5. The multi-sensorial movie is enjoyable

\begin{tabular}{|c|c|c|c|c|}
\hline $\begin{array}{c}\text { Strongly } \\
\text { disagree }\end{array}$ & Disagree & Neutral & Agree & $\begin{array}{c}\text { Strongly } \\
\text { agree }\end{array}$ \\
\hline & & & & \\
\hline
\end{tabular}

